\title{
A PRÁTICA DA ESCRITA: RITMO E SENTIDO
}

The writing practice: rhythm and meaning

\section{Nathália Maria Lopes Dias ${ }^{1}$}

RESUMO: Sabe-se que práticas educativas concernentes ao ensino de língua materna são importantes para o desenvolvimento do desempenho comunicativo nas práticas sociais. $\mathrm{O}$ universo da escrita ainda figura tema de relevantes discussões no cenário educacional brasileiro, especialmente quando posto em comparação ao universo da oralidade. A evolução da língua é fato notório. Dessa forma, é natural que práticas educativas relacionadas a ela também o sejam. É fato ainda que o caráter dinâmico das aulas e a flexibilidade inerente ao processo de ensino e aprendizagem endossam a necessidade de práticas educativas que minimizem o hiato que há, muitas vezes, entre o que já se sabe e as novas experiências ocorridas no ambiente escolar. Outro aspecto que merece atenção é o ritmo da escrita bem como os elementos subjacentes à produção de sentido na dialogicidade peculiares à produção e à recepção do texto. Neste artigo, o que se têm são apontamentos que podem auxiliar no trabalho docente frente a questões inerentes à língua materna. Acredita-se que, à medida que surgirem reflexões acerca da língua, sejam no âmbito da sistematização, sejam no âmbito das múltiplas possibilidades de uso que ela encerra, novas perspectivas surgirão. Estas certamente suscitarão outras e provocarão a continuidade necessária ao ensino enquanto processo cotidianamente construído. Os Parâmetros Curriculares Nacionais (doravante PCN) orientam que, no processo de produção de textos escritos, os alunos devem ser capazes de redigir, com desenvoltura, diferentes tipos de textos. E os sinais de pontuação configuram-se como importantes recursos linguísticos na organização e na produção de sentido textual. Embora a escolha de um ou outro sinal possa estar condicionada à intenção do produtor do texto, em determinadas circunstâncias, o emprego dos sinais de pontuação não varia. Assim, a escrita representa, nesse sentido, a imersão do sujeito nas suas experiências em sociedade também, por isso mesmo é tão importante que essa prática seja, sobretudo, reflexiva.

PALAVRAS-CHAVE: Escrita. Ritmo. Construção de sentido.

ABSTRACT: It is known that educational practices concerning the mother tongue teaching are important for the development of communicative performance in social practices. The universe still figure theme relevant written discussions in the Brazilian educational scenario, especially when set against the world of orality. The evolution of language is notorious fact. Thus, it is natural that educational practices related to it also are. It is true even if the dynamic character of

\footnotetext{
${ }^{1}$ Mestre em Linguística. Professora do Instituto Federal do Piauí. nathaliadias@ifpi.edu.br
} 
the classes and the flexibility inherent in the process of teaching and learning endorse the need for educational practices that minimize the gap that there is often between what is already known and the new experiences that took place in the school environment. Another aspect that deserves attention is the rhythm of writing as well as the elements underlying the production of meaning in the peculiar dialogicity production and text reception. In this article, what you have are notes that can assist in the teaching front work to issues related to the mother tongue. It is believed that, as they arise reflections on language, whether within the systematization, are within the multiple use possibilities it contains, new perspectives emerge. These certainly raise other and cause the necessary continuity to the teaching as daily built process. The National Curriculum Parameters (hereinafter NCPs) guide that, in the production process of written texts, students should be able to write with ease, different types of texts. And the punctuation marks are configured as important linguistic resources in the organization and production of textual meaning. Although the choice of either signal may be conditioned to the intention of the text producer, in certain circumstances, the use of punctuation marks does not vary. Thus, the writing is, in this sense, the subject's immersion in their experiences in society too, so it is so important that this practice is especially reflective.

KEYWORDS: Writing; Practice; Meaning.

\section{O UNIVERSO DA ESCRITA}

As práticas educativas, no âmbito da língua materna, têm sido cada vez mais discutidas a fim de se obter resultados significativos no processo de ensino e aprendizagem. Os debates ainda sobre a influência da oralidade na escrita e sobre os limites pertencentes a uma esfera e/ou outra da linguagem potencializam os inúmeros aspectos inerentes à escrita, dentre eles os mecanismos geradores de ritmo nesse contexto.

\subsection{Aspectos relevantes para o ensino da escrita}

Muitas questões circundam a esfera da escrita, especialmente a abordagem e/ou o olhar que se lança sobre como favorecer todo o conhecimento já adquirido pela criança sobre esse mecanismo no sentido de otimizar seu desenvolvimento quanto às práticas letradas socialmente prestigiadas. Quanto ao papel da escola frente a essas questões, Antunes (2007, p. 37) aponta uma tendenciosa associação da escrita unicamente às normas ditadas pelas gramáticas, numa 
descontextualização recorrente de atividades que pouco ou nada promovem o desempenho linguístico-comunicativo dos discentes.

Reconhece-se, dessa forma, todo o valor agregado à sistematização quanto ao desenvolvimento da prática da escrita alicerçada pelos estudos gramaticais. No entanto, é salutar considerar os demais aspectos que, conjuntamente, tendem a ampliar o conhecimento que o aluno já tem sobre a língua, haja vista que ele, antes de tudo, é um usuário desta língua.

Com o advento da imprensa, segundo Rocha (1997, s/p), um novo olhar foi lançado para a produção escrita. Já é fato notório que uma elaboração escrita se apropria de recursos linguísticos, tais como os sinais de pontuação, que são capazes de conduzir a uma melhor fluência na leitura, além de indiciar o leitor a compartilhar de intenções discursivas do autor, numa concepção interativa com o texto. A esse respeito, diz Castilho: "é claro que escrevemos para alguém que nos leia -, pelo menos, essa é a presunção. Mas a ausência física do leitor nos obriga a desenvolver várias estratégias" (2012, p. 220). Em todo caso, apreende-se a intencionalidade presente no ato da escrita, seja com a presença física ou não de um leitor. O fato é que não se pode minimizar o texto produzido em detrimento de um leitor em potencial. É a interação entre os interlocutores, pois, que é capaz de dinamizar o processo da escrita significativamente.

Sabe-se ainda que a relação do homem com a escrita é muito antiga. Mesmo antes de se convencionalizar a escrita, da forma como se apresenta atualmente, já havia a necessidade do homem de buscar a interação, de procurar se comunicar de alguma forma, como, por exemplo, através de pinturas rupestres. A relação da escrita com a criança, por exemplo, advém muito antes de esta entrar na escola. Ela já participa de eventos de letramento, em menor ou maior escala, a depender do contexto social no qual possa estar inserida, e, portanto, já está incluída no universo da escrita.

Não há como desvincular, dessa forma, todo o conhecimento prévio já trazido pela criança à escola na exploração de questões gramaticais apenas ou na supressão de muitos outros recursos e modalidades perceptíveis e ricamente exploráveis no ensino da língua materna. Percebe-se, como apresenta Antunes (2007), o universo presente na apreensão da própria língua no que tange à escrita:

Com isso se pode concluir, o uso de determinada língua constitui mais que um fato isolado. É mais que um fato especificamente linguístico, vocal ou gráfico. É mais que um exercício prático de emissão de sinais. É um ato humano, social, político, histórico, ideológico, que tem consequências, que tem repercussão na vida de todas as pessoas. É um fato pelo qual passa a história de todos, o sentido de tudo (ANTUNES, 2007, p. 20-21).

A escrita, por sua vez, enquanto elemento favorável à participação nas diversas práticas sociais, apresenta uma possibilidade riquíssima para o desenvolvimento do desempenho 
comunicativo, haja vista que traz um arcabouço de recursos que permite a reflexão sobre o seu funcionamento, bem como sobre suas potencialidades discursivas.

$\mathrm{Na}$ relação entre o universo oral e escrito, reconhecem-se não apenas as peculiaridades de cada um, mas também a dialogicidade que há entre ambos. Nesta perspectiva, Fayol (2014, p. 20) infere sobre o grau de monitoramento saliente na produção escrita como crivo de oposição nesta relação e acrescenta outros fatores que amadurecem essa oposição, como características peculiares na composição da prática escrita, tais como a interatividade e as características físicas das situações e os traços especificamente linguísticos destas.

Para o autor, na produção escrita, além do uso rápido e eficaz dos sinais gráficos, cuja aprendizagem é lenta e difícil, mesmo para a maioria dos adultos, há ainda a lentidão do processo. Neste, o produtor do texto pode desacelerar a produção, planejá-la e modificá-la.

Uma vez admitida essas particularidades, encarar a escrita como um aspecto apenas do espaço escolar, inicialmente, inibe o potencial social inerente a ela. A análise de frases soltas, por exemplo, em nada condiciona a reflexão sobre a dinamicidade complexa do universo da escrita. Tampouco o uso de nomenclaturas ou regras gramaticais garante o trânsito pleno e consciente da competência leitora e escritora pelas possibilidades no uso da língua. A esse respeito, endossa Antunes (2003, p. 50):

em síntese, uma escrita uniforme, sem variações de superestrutura, de organização, de sequência de suas partes, corresponde a uma escrita sem função, artificial, mecânica, inexpressiva, descontextualizada, convertida em puro treino e exercício escolar, que não estimula nem fascina ninguém, pois se esgota nos reduzidos limites das próprias paredes escolares.

Percebe-se, portanto, que é urgente a necessidade de a escola ressignificar sua função quanto ao trato com a escrita, especialmente na exploração de textos, haja vista o caráter social e dinâmico que deve permear o ensino. Além disso, há, no reconhecimento do potencial comunicativo dos alunos, uma ferramenta instigante e criadora na abordagem de questões referentes à escrita dentro do ambiente escolar. A esse respeito, Marcuschi (2008, p. 53) analisa:

é obvio que se a escola tem como missão primária levar o aluno a bem se desempenhar na escrita, capacitando-o a desenvolver textos em que os aspectos formal e comunicativo estejam bem conjugados, isto não deve servir de motivo para ignorar os processos da comunicação oral. A razão é simples, pois desenvolver um texto escrito é fazer as vezes do falante e do ouvinte simuladamente. Mesmo que o texto escrito desenvolva um uso linguístico interativo não do tipo comunicação face a face, deve, contudo, preservar os papéis que cabem ao escritor e ao leitor para cumprir sua função, sob pena de não ser comunicativo.

Isso significa que a prática da escrita é a própria prática social experienciada pelos discentes. Ademais, minimizar o papel do texto na escola é, consequentemente, minimizar a importância das praticas sócias de letramento das quais os alunos fazem parte, além de inibir o 
seu desempenho comunicativo frente a outras práticas socialmente relevantes. Nesse sentido, a escrita representa também a imersão do sujeito nas suas experiências sociais consequentemente.

Outra consideração regente nessas reflexões diz respeito à língua enquanto sistema que propicia interação entre seus usuários, já que apresenta possibilidades complexas em seu uso, especialmente as envolvidas na aprendizagem da escrita. Reconhece-se, como nos mostra Marcuschi (2008, p. 67), que a língua deve permitir, principalmente, que os indivíduos se entendam, além de inseri-los em contextos sócio-históricos.

Em sala, os professores inquietam-se frente à recorrente quebra de expectativas quanto ao domínio da língua escrita padronizada, principalmente, como também dos mecanismos linguísticos que a tornem mais fluente. No entanto, de acordo com Antunes (2007, p. 22-23), o próprio processo de apropriação dessa língua, suas variantes, usos, funções e sistematização não se desvinculam de associações intrínsecas às propriedades gramaticais ainda não convencionadas pela norma padrão. Estas, em sua maioria, encontram apoio na oralidade e, se taxadas apenas como "erros" ou insucesso no desempenho linguístico, comprometem todo o processo de aprendizagem.

Faz-se, portanto, necessário o lançamento de um olhar sistematizado para essa correspondência comum entre oralidade e escrita, realizada pela maioria dos alunos nas escolas públicas brasileiras, especialmente. A partir dessa percepção, surge a necessidade de realização de um trabalho, cujas modalidades da língua, cada uma com suas especificidades, possam favorecer a amplitude das perspectivas comunicativas.

Segundo Antunes (2007, p. 26-27), o aluno, ao chegar à escola, já traz consigo todo um componente de regras de sua gramática internalizada usado na sua comunidade linguística; há toda uma estrutura organizacional na composição de sua fala. O que se nota, no entanto, é que, mesmo inserido em um ambiente escolar, sistematizado, no qual se estudam regras gramaticais apenas e não se estuda a fala, há uma influência considerável dos registros orais nos registros escritos, nas produções textuais feitas pelos alunos, especialmente no ensino fundamental.

É por isso que muitos professores colocam em posições totalmente antagônicas, independentes, o universo da fala e o universo da escrita. Não percebem que, embora com peculiaridades explícitas, a língua escrita e a língua falada compartilham sim de semelhanças que, se trabalhadas consistentemente na apropriação de recursos linguísticos escritos e/ou orais, ressignificam o trabalho com a língua materna em sala de aula e, consequentemente, em seu uso nas práticas sociais.

Para Antunes (2007, p.104), a língua escrita, assim como a falada, é carregada de traços dinâmicos, e pode mudar conforme a necessidade de quem dela se apodera. O papel da escola, 
dentre outros, é possibilitar ao aluno a escolha intencional de qual recurso da língua utilizar, adequando essa escolha às condições de produção, viabilizando a dialogicidade na recepção do material linguístico pelo interlocutor, além de observar outros aspectos, como a esfera social na qual o texto circulará e o seu propósito comunicativo. Assim, no trabalho com o texto escrito em sala de aula, há a necessidade de apontamentos que coloquem em evidência o viés comunicativo do material produzido.

Apesar da unicidade incorporada em alguns aspectos da língua, as variações linguísticas fazem parte do ambiente escolar, especialmente quando se colocam em situação interativa usuários que já trazem consigo marcas linguísticas compartilhadas por suas comunidades e com as quais convivem diariamente (ANTUNES, 2007, p.91). Dessa forma, é perceptível, na produção textual, uma influência significativa da oralidade na escrita que merece ser observada e analisada na apropriação de mecanismos capazes de promover uma escrita intencionalmente elaborada.

Frente a esta complexidade imbricada no ensino de língua materna, a busca de respostas que atendam às exigências do ensino da língua escrita padronizada tem inspirado muitas pesquisas e estudos, especialmente na recorrência de inadequações no uso desse sistema. A esse respeito, Antunes (2003, p. 50) defende que "toda escrita responde a um propósito funcional qualquer, isto é, possibilita a realização de alguma atividade sociocomunicativa entre as pessoas e está inevitavelmente em relação com os diversos contextos sociais em que essas pessoas atuam”.

Nota-se, pois, o viés intencional pelo qual deve perpassar a elaboração do pensamento através da linguagem escrita, sobretudo numa concepção interativa. Essas reflexões sobre a concepção da linguagem em uso no material escrito é que têm subsidiado muitas análises e discussões.

Acerca das acepções relativas à escrita, o ritmo também configura um importante aspecto a ser observado e debatido, haja vista que está diretamente relacionado ao sentido na produção escrita. Dessa forma, a seguir, algumas reflexões serão alocadas nessa perspectiva.

\subsection{Língua escrita: ritmo e sentido}

A organização e o funcionamento da língua estão permeados de questões que vão além do meramente estilístico. Há, na composição dela, aspectos rítmicos que condicionam muitas ocorrências, seja no plano oral e/ou escrito. Essas ocorrências, apesar de apresentarem pontos divergentes, desenvolvem a produção de sentido tanto na escrita quanto na oralidade. Chacon 
(1998, p. 21) afirma que, na linguagem, o ritmo é gerador de sentido e vice-versa. Assim, o ritmo estaria presente na produção de sentido na linguagem em uso.

Através do estabelecimento das relações de sentido entre as unidades rítmicas, percebe-se o valor, principalmente semântico, atribuído às marcas de pontuação. Chacon (1998, p. 90), ao discorrer sobre a organização rítmica por meio das marcas gráficas que compõem a significação no discurso, mostra a percepção das gramáticas tradicionais no tocante à concepção semântica operacionalizada pelos sinais de pontuação.

Numa relação com os sinais de pontuação, ainda que o ritmo na escrita não seja comumente abordado nos estudos tradicionais de linguagem, o autor reconhece que esses estudos anteriores e tradicionais, mesmo que não intencionalmente, apontaram contribuições importantes para as relações semânticas que o ritmo estabelece na escrita.

Como se pode perceber, nos vínculos que estabelecem entre as sequências de palavras,
os sinais de pontuação criam, entre as partes que (por meio desse vínculo) se alternam
ritmicamente, relações de sentido que tornam possível prever as diferentes orientações
que a significação tomará num texto escrito. (CHACON, 1998, p. 121).

Com isso, apreende-se que o ritmo da escrita contribui para a concepção semântica do texto.

No campo das propriedades da atividade gráfica, para Chacon (1998, p. 51), “o ritmo está na base da própria definição do que vem a ser a escrita, possibilitando sua constituição e funcionamento, consequentemente, como um dos mecanismos mais elementares". Dessa forma, é possível inferir a proximidade entre o ritmo na escrita e as atividades com a oralidade. No entanto, segundo autor, é importante salientar que a dimensão escrita tem um ritmo que lhe é próprio, apesar de que, em algumas ocorrências, esse ritmo vem como a representação gráfica da oralidade.

Por outro lado, segundo Corrêa (1994, p 55), ao se observar o ritmo da escrita, tem-se o movimento do texto, que lhe é particular. Trata-se de um movimento capaz de estabelecer articulações entre as partes do texto. Embora se reconheça as especificidades do ritmo da escrita, a leitura em voz alta é capaz de recodificar o seu ritmo, uma vez que há uma ocorrência simultânea entre o reconhecimento das marcas gráficas e a (re) interpretação do texto. Para Corrêa (1994, p. 55), o ritmo da escrita perpassa pela percepção da pontuação, da coesão e do movimento do texto: "no contexto da nossa reflexão, o movimento poderia ser, portanto, não só a passagem de um espaço a outro no interior do texto escrito, como também a passagem de um intervalo temporal a outro no âmbito do texto oral". A partir dessa possibilidade, o texto ganharia de fato seu movimento, sua coesão interna. 
Segundo o autor, a pontuação correlativa, ligada ao ritmo da escrita, ao configurar um movimento particular para o texto, caracteriza-se como um dos recursos gráficos para o estabelecimento da coesão textual. A pontuação correlativa, portanto, estaria no texto para indicar a separação de unidades incluídas através da vírgula, uma no começo e outra no final. Não apenas como recurso gráfico, a pontuação, capaz de isolar partes do enunciado é, antes, a responsável pela integração semântica do texto como um todo. Assim, o ritmo da escrita, na tessitura material, está ligado a marcas gráfico-visuais na promoção do movimento do texto.

Chacon (1998, p. 64-79) e Corrêa (1994, p. 54), no que concerne às acepções acerca do ritmo da escrita, lançam mão dos estudos de Abaurre (1996) sobre a contribuição dos sinais de pontuação para as percepções rítmicas. Chacon (1998) assim sintetiza:

1) o ritmo da escrita refere-se às estruturas materiais da linguagem e à sua significação, já que o sentido e seu suporte linguístico material se distribuem organizada e espacialmente no texto. O ritmo da escrita seria, assim, o ritmo da espacialização do sentido no texto, a partir do seu suporte material;

2) o ritmo da escrita constrói-se na textualidade. $\mathrm{Na}$ base da organização textual da linguagem, ele se encontra, pois, promovendo a coesão dos elementos de um texto e criando, através do vínculo coesivo, um movimento próprio a esse texto;

3) o ritmo da escrita é indiciado pelos sinais de pontuação, na medida em que tais marcas gráfico-visuais podem pôr em realce categorias textuais que, relacionadas, promovem o movimento do texto. Destaca-se, portanto, o caráter metodológico da pontuação na análise do ritmo da escrita. (CHACON, 1998, p. 82-83).

Dessa forma, tem-se na escrita aspectos marcadamente específicos quanto à produção de ritmo e sentido. Nessas reflexões, buscou-se ampliar a concepção sobre os aspectos demarcadores de ritmo no texto escrito de forma a fomentar também estudos posteriores que possam contribuir para o processo de ensino e aprendizagem. Além disso, considera-se importante o conhecimento sobre as dimensões rítmicas para a estruturação do texto escrito.

As discussões sobre o ensino de língua materna possibilitam amadurecer a ideia de que o ambiente escolar é, por excelência, o lugar onde a prática da leitura e da escrita é iniciada e desenvolvida, pelo menos para a maioria dos brasileiros. No entanto, ainda são preocupantes os resultados quanto à aplicação dos recursos disponíveis na língua para o desempenho comunicativo. Dentre esses recursos, os sinais de pontuação assumem um caráter substancial nos diversos gêneros textuais que circulam na sociedade. Ademais, reconhece-se, na dinamicidade da língua, a importância de se discutir também sobre o ensino de gramática nas escolas e sobre as perspectivas adotadas pelo professor para o alcance de resultados significativos no processo de ensino e aprendizagem, haja vista que não há uma singularidade no direcionamento do trabalho docente frente a questões que envolvem a língua materna. 


\section{Considerações finais}

No desenvolvimento da competência comunicativa, o texto, tratado tanto como forma de conhecimento quanto como fonte de prazer e descoberta, assume um papel singular que vai desde a ampliação do léxico, passa pelo viés criativo, inventivo, chegando mesmo a repercutir em suas práticas sociais e a ser reflexo destas, por conseguinte.

Os fenômenos da língua se relacionam com uma gama de conhecimentos outros que vão além do puramente cognitivo ou gramatical. Têm-se claramente perceptíveis culturas de letramento que atingem diferentes segmentos sociais, portanto, conotam práticas sociais diversas nos muitos usos da linguagem. $\mathrm{Na}$ sala de aula, no trato com a linguagem, a sensibilidade linguística suscita possibilidades tanto no uso da língua quanto na ativação da competência leitora e/ou escritora.

O texto escrito goza de certo prestígio na sala de aula. Tal realidade não admite que se trate dessa especificidade ignorando-o enquanto produto social valoroso em práticas sociais de letramento em diferentes concepções, socialmente prestigiadas.

Isso significa que a prática da escrita é a própria prática social experienciada pelos discentes. Ademais, minimizar o papel do texto na escola é, consequentemente, minimizar a importância das praticas sócias de letramento das quais os alunos fazem parte como também inibir o seu desempenho comunicativo frente a outras práticas socialmente relevantes.

Avalia-se, por fim, este estudo como uma experiência positiva que pode promover muitos outros questionamentos acerca do tema ora discutido. Ademais, reconhece-se, na dinamicidade da língua, a importância de se discutir também sobre o ensino de gramática nas escolas e sobre as perspectivas adotadas pelo professor para o alcance de resultados significativos no processo de ensino e aprendizagem, haja vista que não há uma singularidade no direcionamento do trabalho docente frente a questões que envolvem a língua materna. 


\section{REFERÊNCIAS:}

ANTUNES, Irandé. Aula de português: encontro e interação. São Paulo: Parábola Editorial, 2003.

Muito além da gramática: por um ensino sem pedras no caminho. São Paulo: Parábola Editorial, 2007.

CASTILHO, Ataliba, T. Nova Gramática do português brasileiro. 1. ed., $2^{\mathrm{a}}$ reimpressão - São Paulo: Contexto, 2012.

CHACON, L. Ritmo da escrita: uma organização do heterogêneo da linguagem. São Paulo: Martins Fontes, 1998.

CORRÊA, M. L. G. Pontuação: sobre seu ensino e concepção. Leitura. Teoria e Prática, 24, pp. 52-65, 1994.

FAYOL, Michel. Aquisição da escrita.Tradução Marcos Bagno - 1 ed. - São Paulo: Parábola Editorial, 2014

MARCUSCHI, Luiz Antônio. Produção textual, análise de gêneros e compreensão. São Paulo: Parábola Editorial, 2008.

ROCHA, Iúta Lerche Vieira. O sistema de pontuação na escrita ocidental: uma retrospectiva. DELTA, São Paulo, v. 13, n. 1, p. 83-118, fev. 1997. Disponível em http://www.scielo.br/scielo.php?script=sci_arttext\&pid=S010244501997000100005\&lng=pt\&nr $\mathrm{m}=$ iso $>$. acessos em 12 maio 2016. http://dx.doi.org/10.1590/S0102-44501997000100005. 